\title{
Numerical Investigation of the Effect of Process Parameters during Aluminium Wheel Flow-Forming
}

\author{
So Young Hwang - Naksoo Kim $-{ }^{*}$ Cheol-soo Lee \\ Sogang University, Department of Mechanical Engineering, Korea
}

Aluminium wheel flow-forming is an incremental forming technique that lengthens the material in the axial direction and thins it in the radial direction. There are many advantages to wheel flow-forming, including reducing the weight of the product, which leads to improved fuel economy. However, in terms of geometric accuracy, it is difficult to manufacture with high precision. In this study, process conditions, such as headstock load, feed rate, and radial compression, as well as the geometry of the rolls, are investigated to improve the precision of the product. To do this, a simulation was performed with SHAPE-RR, a type of FEM software. The result of the FE analysis was verified by comparing the bulging amount of the wheel. The material property of aluminium was determined through a hot compression test. As a result, geometric accuracy was improved by increasing the feed rate of the rolls. Moreover, applying a lower compression amount in the radial direction for the third roll increased the geometric precision.

Keywords: aluminium wheel flow forming, backflow defect, geometric precision, compression amount

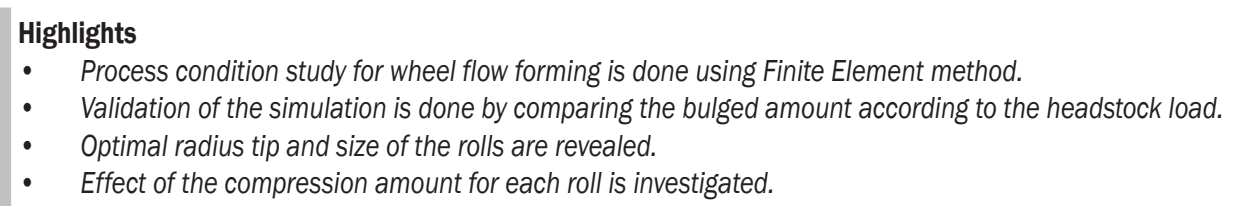

\section{INTRODUCTION}

Ecofriendly, lightweight, and high-efficiency are the most important key words in manufacturing fields, especially the automobile industries. There have been many studies on lightweight automotive design [1] to [4]. For this, reducing the weight of the wheels can be a solution. Both steel wheels and aluminium alloy wheels for passenger cars are used. The aluminium wheel's weight can be one-third less than that of a steel wheel. If the weight below the spring of the automobile is reduced by $1 \mathrm{~kg}$, the total weight of the car can be reduced 10 to $15 \mathrm{~kg}$ [5]. This can lead to higher efficiency and more environmentally friendly automobiles.

Aluminium wheels can be manufactured by casting or by casting followed by flow forming. Friction stir welding can also be used for the production of aluminium wheels, and many studies have been conducted on this technique [6] to [10]. If flow forming is included in the manufacturing process, the weight can be reduced by 10 to $18 \%$ because the mechanical characteristics are improved. During aluminium flow forming, three side rolls are used. The first roll starts to operate when the process begins and the second roll begins to operate a few seconds later, followed by the third roll. The three rolls operate at the same time during the process except at the beginning and the end.
However, because of its complicated shape, there is no systematic design approach to determine the optimal process condition to increase geometric accuracy. Therefore, in the field, manufacturers rely on trial-and-error methods to find the best process condition.

Many studies have been performed to understand the flow-forming process. Wong et al. reviewed the principles and developments of flow forming and insisted on the great potential of manufacturing complex shapes [11]. Yao and Murata experimentally investigated the process parameters, including feed rate, radial force, and surface roughness, for aluminium tube flow forming [12]. Molladavoudi and Djavanroodi experimentally investigated the effects of thickness reduction on the mechanical properties and spinning accuracy [13]. Lee and Lu demonstrated the relationship between the load of roller and mandrel to the strain rate and surface roughness. They also confirmed that it is beneficial to have larger rollers since the surface finishing is better than with smaller rollers [14]. Davidson et al. found that the depth of cut in turning operation is an important process parameter affecting the percentage of elongation, by using the Taguchi method [15].

While many experimental studies on flow forming have been done, there also have been studies using the finite element method (FEM) to investigate the flow forming process. $\mathrm{Xu}$ et al. used a $3 \mathrm{D}$ rigid 
plastic model to establish an FEM model of tube spinning, and the model was verified experimentally [16]. Xia et al. studied the effect of the main forming parameters, such as offset amount, feed rate, and path direction, on the spinning forces, theoretically and experimentally, using a finite element (FE) simulation [17].

Research exists on the defects that occur during spinning or flow forming, but it remains at the level of simulating and verifying the phenomenon by comparing experimental and analytical results. However, in the field, it is important to achieve the precise feature that is desired. Therefore, the purpose of this study is to understand the effect of the process parameters of headstock load, compression amount, feed rate, and roll shape on the geometric accuracy. To do this, a sensitivity analysis was performed using FE analysis to determine the effect of the process variables on the geometric accuracy. The SHAPE-RR program, which is exclusively used for the rotational manufacturing process, was used for FE analysis. To verify the validity of this analysis, the bulging amounts from the analytical and experiment results were compared, which was the verification method used by Mohebbi and Akbarzadeh to enhance the reliability of the FE analysis [18].

\section{BACKFLOW DEFECT}

According to Cha et al., the so-called backflow defect occurs during the wheel flow-forming process [19]. Therefore, backflow must be reduced to enhance the geometric accuracy. The backflow defect is a bulging phenomenon located on the opposite side of the forming direction.

As shown in Fig. 1, when the roller applies a load to a part where the diameter rapidly varies, the resultant load can be divided into radial and axial forces. The radial force reduces the thickness of the material, and the axial force elongates in the axial direction. When the roller is used to reduce the thickness, a material point is moved in the opposite direction of the roller movement to cancel out the axial force. Moreover, when the load of the headstock is enormous, backflow is generated, which creates the bulging defect, as shown in Fig. 1.

According to Cha et al. [19], the amount of bulging is related to the headstock load. If the headstock load is excessive, the reaction force on the headstock is increased, which leads to a greater amount of bulging. However, if the headstock load is insufficient, the wheel will lift up from the mandrel, which affects the precision of the product. Therefore, the optimal headstock load must be studied.

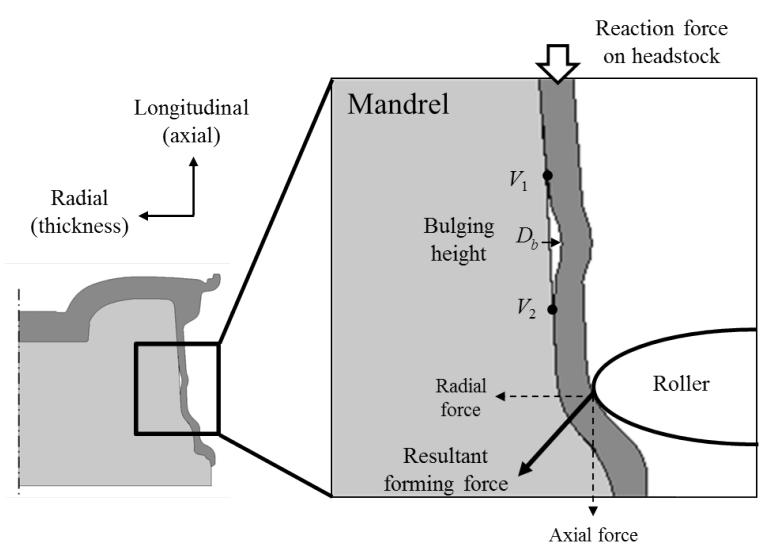

Fig. 1. Mechanism of backflow defect

\section{WHEEL FLOW-FORMING MODEL}

To perform a sensitivity analysis of the wheel flow forming process, the SHAPE-RR program, which was developed based on the FEM, was used. Prior to the computation analysis, the material properties of aluminium had to be determined, and the validity of the analysis program had to be verified.

\subsection{Material Characteristics}

To describe the material flow during wheel flow forming, the Johnson-Cook flow stress model shown in Eq. (1) was used. In the equation, $\bar{\varepsilon}^{p l}$ is the effective plastic strain, $\dot{\bar{\varepsilon}}^{p l}$ the effective plastic strain rate, and $T_{\text {melt }}$ is the melting temperature. This is suitable for considering the strain rate and temperature terms because wheel flow forming is a bulk deformation process with time-dependency.

$$
\begin{gathered}
\sigma_{f}=\left(A+B\left(\bar{\varepsilon}^{p l}\right)^{n}\right)\left(1+C \ln \dot{\bar{\varepsilon}}^{p l}\right)\left(1-T^{* m}\right), \\
T^{*}=\frac{T-T_{\text {room }}}{T_{\text {melt }}-T_{\text {room }}} .
\end{gathered}
$$

The Johnson-Cook model uses $A, B, n, C$ and $m$ as material coefficients. Friction and these coefficients were obtained through a hot compression test. The dimensions of the cylindrical specimen are a length of $40 \mathrm{~mm}$ and a diameter of $15 \mathrm{~mm}$. To obtain the terms of strain rate and temperature, five experimental cases were set. The initial temperature of the aluminium specimen for the flow forming process was $360{ }^{\circ} \mathrm{C}$. Therefore, the experimental conditions of temperature 


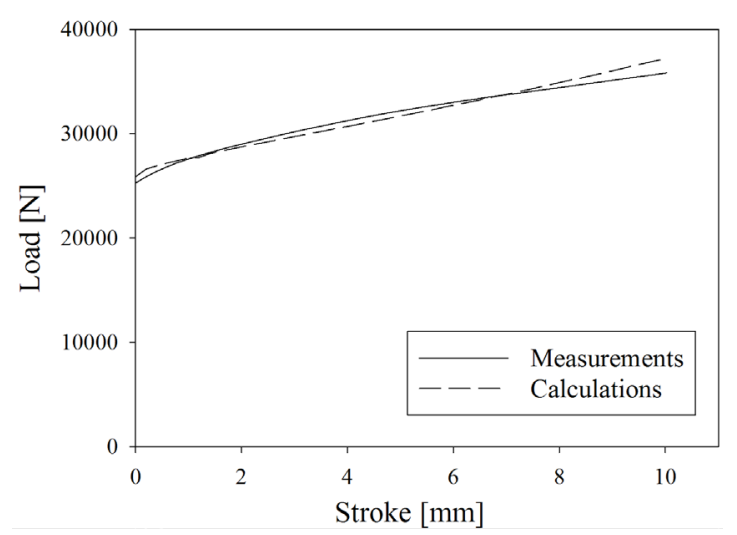

Fig. 2. Comparison of experiment and simulation for $330{ }^{\circ} \mathrm{C}-10 \mathrm{~mm} / \mathrm{min}$

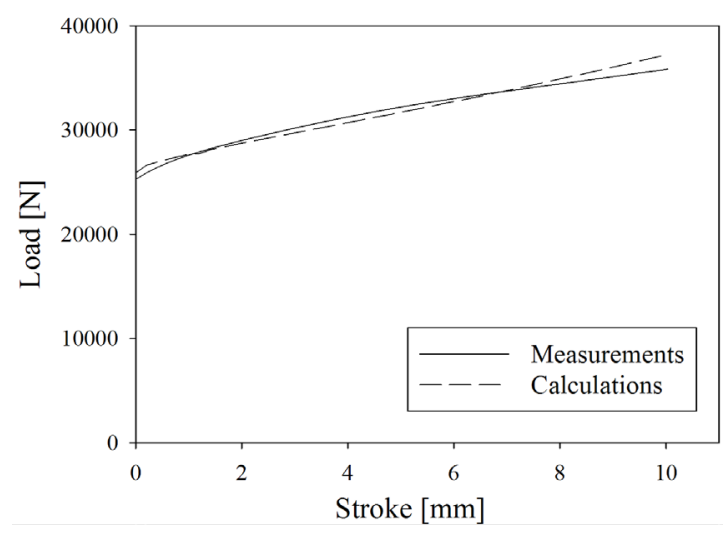

Fig. 3. Comparison of experiment and simulation for $360^{\circ} \mathrm{C}-10 \mathrm{~mm} / \mathrm{min}$

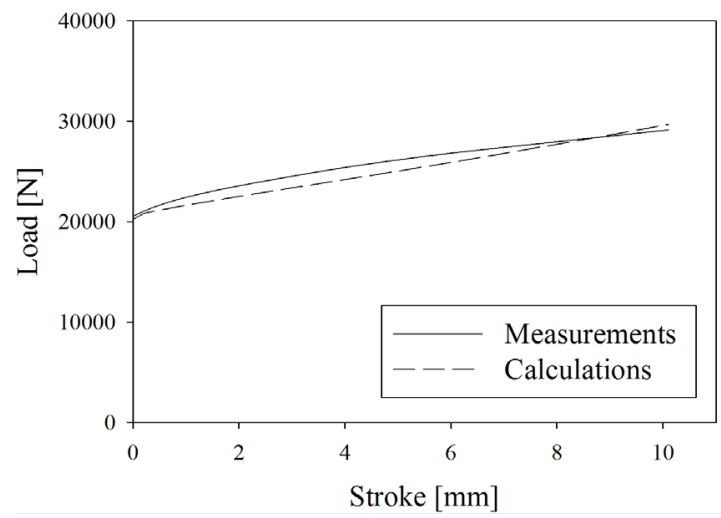

Fig. 4. Comparison of experiment and simulation for $390{ }^{\circ} \mathrm{C}-10 \mathrm{~mm} / \mathrm{min}$

were considered to be $390{ }^{\circ} \mathrm{C}$ and $330{ }^{\circ} \mathrm{C}$. Each case was repeated three times.

After obtaining the load-stroke curve from the experiment, it was averaged for each case. The coefficients and the friction that minimized the load-stroke curve between the experiment and the simulation were obtained. The coefficients are shown in Table 1, and the friction coefficient is 0.2 . The loadstroke curves obtained from the experiment and the simulation are compared for each case in Figs. 2, 3, and 4.

Table 1. Material coefficients of the Johnson-Cook model

\begin{tabular}{cccccc}
\hline$A$ & $B$ & $n$ & $C$ & $m$ & $T_{\text {melt }}$ \\
\hline $154 \mathrm{MPa}$ & $63 \mathrm{MPa}$ & 0.476 & 0.015 & 1.0 & $887 \mathrm{~K}$ \\
\hline
\end{tabular}

\subsection{Simulation Model}

The wheel flow forming simulation model is shown in Fig. 5. Three-dimensional eight-node solid elements were used in the model. The second and third rollers were placed $125^{\circ}$ from the first roller, which put them $115^{\circ}$ from each other.
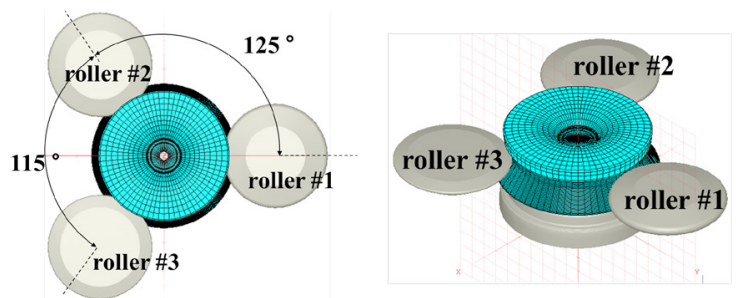

Fig. 5. Full FE model of wheel flow forming

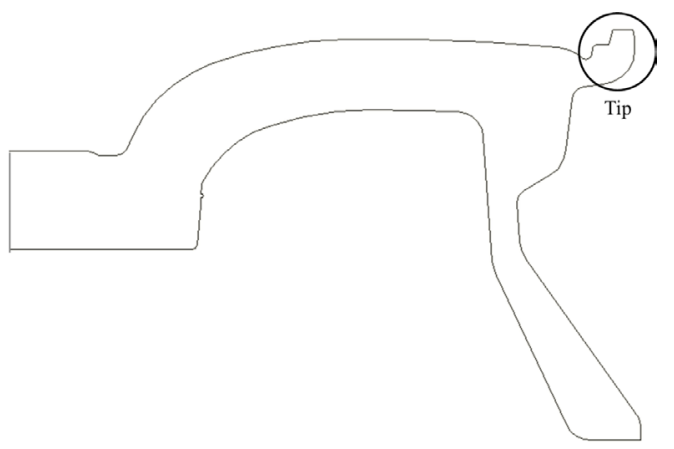

a)

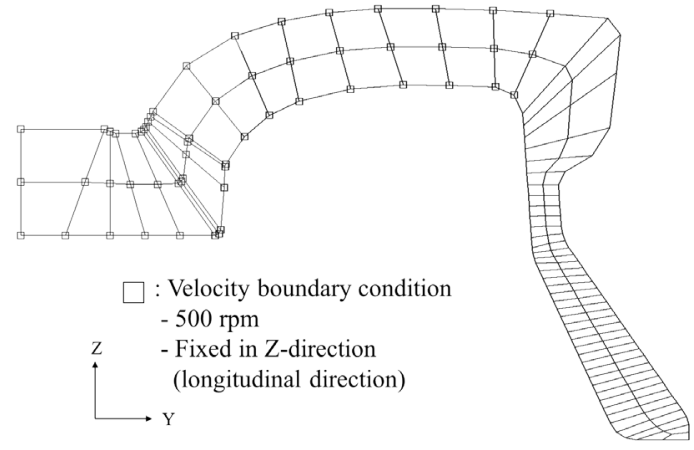

Fig. 6. Numerical model for the cross-section of the wheel; a) actual shape, and b) simplified finite element mesh

To increase the computational efficiency, a complicated shape in the corner of the work piece, 
shown in Fig. 6a, was removed. A mesh test was also performed to determine the maximum size of the mesh. The longitudinal mesh length on the side was studied, and with the same forming condition, the geometrical difference was compared, and $4 \mathrm{~mm}$ was chosen. The cross-section of the initial work piece and the boundary condition are shown in Fig. 6b. The boundary condition is given as $500 \mathrm{rpm}$.

\subsection{Simulation Validation}

To validate the reliability of the simulation, the amount of bulging according to headstock load was compared with the experimental model. The obtained material properties were applied to the simulation. At each load condition, three experiments were conducted to ensure the accuracy of the results. The initial work piece and the flow-formed wheel are shown in Fig. 7.

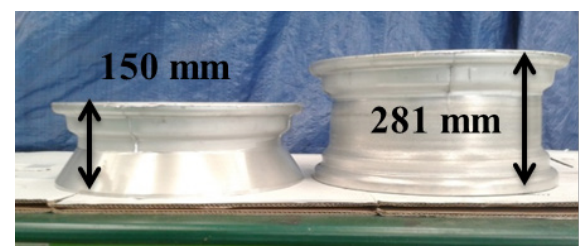

Fig. 7. Initial work piece and manufactured wheel

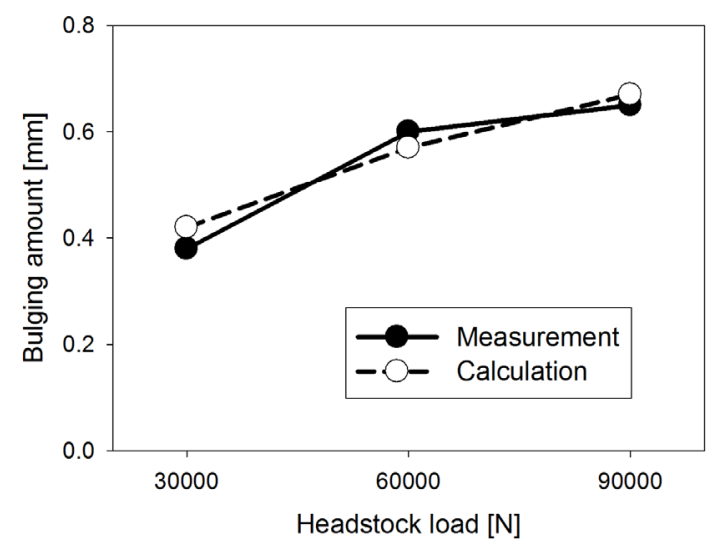

Fig. 8. Comparison of experiment and simulation of bulging amount

As shown in Fig. 8, the amount of bulging tends to increase as the load increases. This is because the load in the longitudinal direction is related to the bulging mechanism, as explained in Section 1. The amount of bulge converges at the end because of the geometric limitations.

As shown in Fig. 8, the averaged bulging amount of the experimental model and the simulation is similar, with a $6 \% \%$ difference between them.

\section{GEOMETRIC ACCURACY}

Manufacturing the product with high geometric accuracy is the most important factor during the wheel flow-forming process. If it is accurate, the cutting process afterwards will be reduced.

To perform a sensitivity analysis, simulation conditions have to be determined. The location of the rolls and the work piece during the process is shown in Fig. 5. Three side rolls were placed, as shown in Fig. 5.

The gap between the mandrel and the work piece after the forming process was calculated as the crosssection area between them (Fig. 9). During wheel flow forming, the work piece is lifted up from the mandrel, which creates a gap. This gap has to be minimized to increase the geometric accuracy.

First, it is important to investigate the effect of headstock load on the geometric accuracy. As mentioned in the prior chapter, it is important to determine the suitable headstock load. If the load is too high, the bulging amount will increase. However, if the headstock does not have enough force to settle the work piece down onto the mandrel, the work piece is lifted up from the mandrel. Therefore, according to the headstock load, the gap between the mandrel's top surface and the work piece is calculated. As a result, with a higher load, the gap is reduced (Fig. 10).

However, a headstock load over $60,000 \mathrm{~N}$ creates bulging of over $0.5 \mathrm{~mm}$, which is the limitation. Furthermore, the gap must be less than $400 \mathrm{~mm}^{2}$ for the wheel to be a non-defective product. If the gap exceeds $400 \mathrm{~mm}^{2}$, then the wheel cannot become used because of the geometry tolerance. Therefore, 30,000 $\mathrm{N}$ is the most appropriate headstock load.

Second, the shapes of the side-rolls were investigated. Specifically, the diameter of the roll and the radius of the roll-tip is considered. The level of each parameter is shown in Table 2. In this table, $r_{1}$ indicates the radius of the tip for the first roll, and $r_{2}$ indicates the radius of the tip for the second roll. The tip radius of the third roll was not considered because it is the finishing roller. The upper bound was determined according to the limitations of geometry.

To run an efficient amount for the experiment, the Taguchi method was used. Three variables with three levels fit the L9(34) orthogonal array. Therefore, a total of nine cases were simulated. For each case, the gap difference was calculated as shown in Table 3, and this was used to obtain the objective function as shown in Eq. (3):

$$
y=1093-110.5 r_{1}-34 r_{1}+2 R+3.3 r_{1}^{2}+2.4 r_{2}^{2} .
$$


By optimizing the objective function using the response surface method [20], the optimum values for each parameter to maximize the geometric accuracy were $r_{1}=20 \mathrm{~mm}, r_{2}=12.7 \mathrm{~mm}$, and $R=176 \mathrm{~mm}$.

The results indicate that the first roller must have the largest tip radius. The role of the first roll is to push down the material so that it can be flow-formed close to the mandrel. If the tip radius is large, it will be easier for the roller to push down the material, which makes it easier for the second and third rolls to shape the wheel.

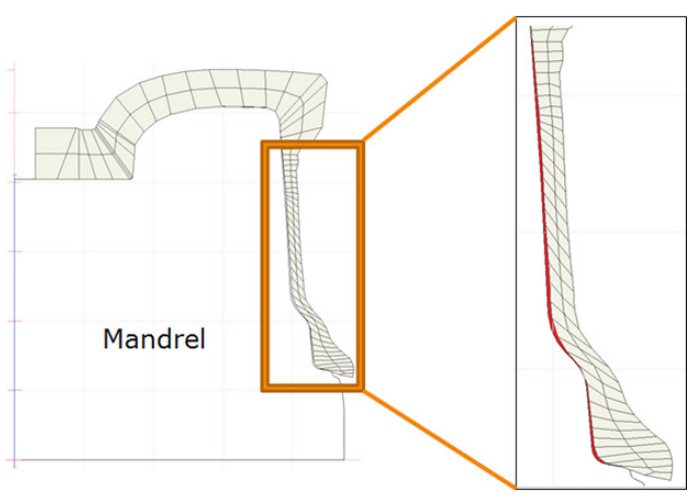

Fig. 9. Gap between mandrel and material

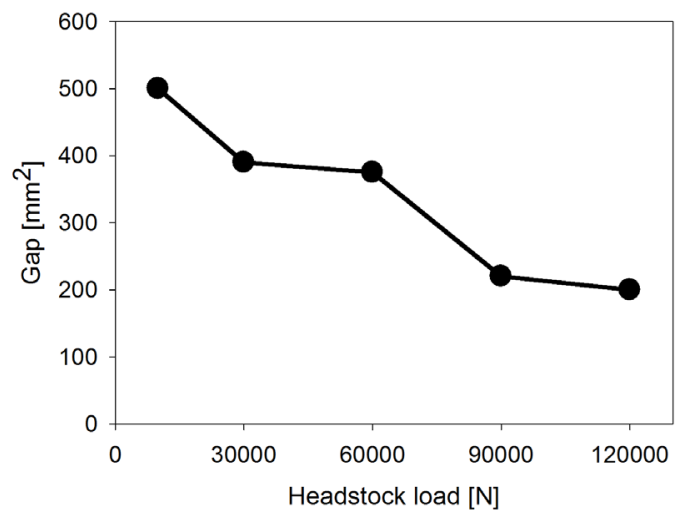

Fig. 10. Gap according to headstock load

In contrast, the compression amount of each roll was considered. As explained above, three side-rolls were used during the process, and the radial thickness that had to be reduced was $10 \mathrm{~mm}$. Therefore, the amount of compression for each roll was adjustable, so the compression amounts of the rolls were investigated. Parameter $d_{2}$ indicates the compression amount in the radial direction of the second roll and $d_{3}$ represents this for the third roll. Automatically, the compression amount of the first roll is the rest of the $10 \mathrm{~mm}$. Table 4 shows the results. As the compression amount is small for the third roll, it has a better geometric precision. This is because the third roll is the last roll, which affects the final shape of the work piece. Therefore, as much as the first roll compresses, it is easier for the second and third rolls to form precise geometries.

Table 2. Roll-shape parameters and levels

\begin{tabular}{cccc}
\hline & $r_{1}[\mathrm{~mm}]$ & $r_{2}[\mathrm{~mm}]$ & $R[\mathrm{~mm}]$ \\
\hline Level 1 & 10 & 10 & 120 \\
\hline Level 2 & 15 & 15 & 180 \\
\hline Level 3 & 20 & 20 & 240 \\
\hline
\end{tabular}

Table 3. Taguchi method matrix

\begin{tabular}{cccccc}
\hline & $r_{1}[\mathrm{~mm}]$ & $r_{2}[\mathrm{~mm}]$ & $R[\mathrm{~mm}]$ & Error & Gap [mm²] \\
\hline 1 & 10 & 10 & 120 & 1 & 315 \\
\hline 2 & 10 & 15 & 180 & 2 & 347 \\
\hline 3 & 10 & 20 & 240 & 3 & 401 \\
\hline 4 & 15 & 10 & 180 & 3 & 209 \\
\hline 5 & 15 & 15 & 240 & 1 & 199 \\
\hline 6 & 15 & 20 & 120 & 2 & 469 \\
\hline 7 & 20 & 10 & 240 & 2 & 258 \\
\hline 8 & 20 & 15 & 120 & 3 & 332 \\
\hline 9 & 20 & 20 & 180 & 1 & 463 \\
\hline
\end{tabular}

Table 4. Geometric accuracy according to compression amount

\begin{tabular}{cccc}
\hline & $d_{2}[\mathrm{~mm}]$ & $d_{3}[\mathrm{~mm}]$ & Gap $\left[\mathrm{mm}^{2}\right]$ \\
\hline Case 1 & 3 & 2 & 191.7 \\
\hline Case 2 & 4 & 2 & 238.5 \\
\hline Case 3 & 3 & 1 & 130.2 \\
\hline
\end{tabular}

Table 5. Geometric accuracy according to feed rate

\begin{tabular}{ccc}
\hline & Feed rate [mm/rev] & Gap [mm²] \\
\hline 1 & $1.7 \mathrm{~mm} / \mathrm{rev}$ & 146.9 \\
\hline 2 & $1.6 \mathrm{~mm} / \mathrm{rev}$ & 149.5 \\
\hline 3 & $1.5 \mathrm{~mm} / \mathrm{rev}$ & 165.6 \\
\hline 4 & $1.4 \mathrm{~mm} / \mathrm{rev}$ & 166.1 \\
\hline 5 & $1.3 \mathrm{~mm} / \mathrm{rev}$ & 201.9 \\
\hline
\end{tabular}

Finally, the feed rate was considered. The feed rate refers to the speed in the longitudinal direction while rotating. Therefore, $1.5 \mathrm{~mm} / \mathrm{rev}$ means that the roller moves downward at $1.5 \mathrm{~mm}$ per revolution, and this is related to the forming process time. For each feed rate considered, the result is shown in Table 5. Case 1 is when the forming process was done in 14 seconds. As shown in Fig. 11, the gap, or the form error, is reduced as the feed rate increases. However, after $1.6 \mathrm{~mm} / \mathrm{rev}$, the gap between the mandrel and the work piece converges to $145 \mathrm{~mm}^{2}$.

\section{CONCLUSIONS}

In this research study, the process conditions that can affect geometric precision were studied. The first 
factor that was considered was the headstock load, which is the main cause of bulging defects. As this is increased, the bulging amount increases. However, the lifted gap between the work piece and the mandrel decreases as the headstock loads increase. Considering that both factors are equally important, $30,000 \mathrm{~N}$ is the most proper headstock load for the presented case study. Furthermore, for the first roll, it is better to have a large tip radius. Due to geometric limitations, 20 $\mathrm{mm}$ is the largest tip radius. In contrast, the optimal tip radius of the second roll is $12.7 \mathrm{~mm}$. In terms of compression amount, it is better for the first roll to compress more and to reduce the compression amount for the second and third rolls for geometric precision. The gap can be reduced down to $130.2 \mathrm{~mm}^{2}$. For the feed rate, which is related to process time, it is better for it to be fast. When the feed rate is over $1.6 \mathrm{~mm} /$ rev, the gap is less than $150 \mathrm{~mm}^{2}$. These results only consider the geometric precision. Finally, this study can be extended to considering the lifespan of the rolls.

\section{ACKNOWLEDGMENTS}

This work was supported by Sogang University (Grant no. 201210031) and the National Research Foundation of Korea (NRF) grant, funded by the Korean Government (NRF-2010-0023152).

\section{REFERENCES}

[1] Belingardi, G., Beyene, A.T., Koricho, E.G., Martorana, B. (2015). Alternative lightweight materials and component manufacturing technologies for vehicle frontal bumper beam. Composite Structures, vol. 120, p. 483-495, D0I:10.1016/j. compstruct.2014.10.007.

[2] Jiang, J., Wang, Y., Chen, G., Liu, J., Li, Y., Luo, S. (2012). Comparison of mechanical properties and microstructure of AZ91D alloy motorcycle wheels formed by die casting and double control forming. Materials and Design, vol. 40, p. 541549, D0I:10.1016/j.matdes.2012.04.029.

[3] Kobold, D., Pepelnjak, T., Gantar, G., Kuzman, K. (2010). Analysis of deformation characteristics of magnesium AZ80 wrought alloy under hot conditions. Strojniški vestnik- - Journal of Mechanical Engineering, vol. 56, no. 12, p. 823-832.

[4] Hirsch, J., Al-Samman, T. (2013). Superior light metals by texture engineering: Optimized aluminum and magnesium alloys for automotive applications. Acta Materialia, vol. 61, no. 3, p. 818-843, D0l:10.1016/j.actamat.2012.10.044.

[5] Jambor, A., Beyer, M. (1997). New cars-new materials. Material \& Design, vol. 18, pp. 203-209, D0l:10.1016/S02613069(97)00049-6.

[6] Besharati-Givi, M.K., Asadi, P. (eds.) (2014) Advance in Friction Stir Welding and Processing. Woodhead Publishing, Cambridge.
[7] Kallee, S., Nicholas, D. (1998). Application of friction stir welding to lightweight vehicles. SAE Technical Paper, 982362 , DOl:10.4271/982362.

[8] Podržaj, P., Jerman, B., Klobčar, D. (2015). Welding defects at friction stir welding. Metalurgija, vol. 54, no. 2, p. 387-389.

[9] Klobčar, D., Kosec, L., Pepelnjak, T., Tušek, J. (2012). Microstructure and mechanical properties of friction stir welded AlMg4.5Mn alloy. Engineering Review, vol. 32, no. 2, p. 104-110.

[10] Herakovic, N., Simic, M., Trdic, F., Skvarc, J. (2011). A machinevision system for automated quality control of welded rings. Machine Vision and Applications, vol. 22, no. 6, p. 967-981, D0I:10.1007/s00138-010-0293-9.

[11] Wong, C.C., Dean, T.A., Lin, J. (2003). Review of spinning, shear forming and flow forming processes. Journal of Machine Tools and Manufacture, vol. 43, no. 14, p. 1419-1435, DOI:10.1016/S0890-6955(03)00172-X.

[12] Yao, J., Murata, M. (2002). An experimental study on paraxial spinning of one tube end. Journal of Materials Processing Technology, vol. 128, no. 1-3, p. 324-329, Dol:10.1016/ S0924-0136(02)00473-9.

[13] Molladavoudi, H.R., Djavanroodi, F. (2011). Experimental study of thickness reduction effects on mechanical properties and spinning accuracy of aluminum 7075-o during flow forming. International Journal of Manufacturing and Technology, vol. 52, no. 9-12, p. 949-957, Dol:10.1007/s00170-010-2782-4.

[14] Lee, K.S., Lu, L. (2001). A study on the flow forming of cylindrical tubes. Journal of Materials Processing Technology, vol. 113, no. 1-3, p. 739-742, D0I:10.1016/S09240136(01)00585-4.

[15] Davidson, M.J., Balasubramanian. K., Tagore, G.R.N. (2008). Experimental investigation on flow-forming of AA6061 alloy--A Taguchi approach. Journal of Materials Processing Technology, vol. 200, no. 1-3, p. 283-287, Dol:10.1016/j. jmatprotec.2007.09.026.

[16] Xu, Y., Zhang, S.H., Li, P., Yang, K., Shan, D.B., Lu, Y. (2001). $3 \mathrm{D}$ rigid-plastic FEM numerical simulation on tube spinning. Journal of Materials Processing Technology, vol. 113, no. 1-3, p. 710-713, DOI:10.1016/S0924-0136(01)00644-6.

[17] Xia, Q.X., Xie, Sh., W., Huo, Y.L., Ruan, F. (2008). Finite element simulation and experimental investigation on the forming forces of 3D non-axisymmetrical tubes spinning. Journal of Materials Processing Technology, vol. 206, no. 1-3, p. 500508, D0I:10.1016/j.jmatprotec.2007.12.066.

[18] Mohebbi, M.S., Akbarzadeh, A. (2010). Experimental study and FEM analysis of redundant strains in flow forming of tubes. Journal of Materials Processing Technology, vol. 210, no. 2, p. 389-395, D0l:10.1016/J.jmatprotec.2009.09.028.

[19] Cha, W.G., Hwang, S.Y., Kim, N., Lee, C.S. (2014). Analysis of mechanism of backflow defect of the aluminum wheel flow forming. Journal of Precision Engineering and Manufacturing, vol. 15, no. 6, p. 1075-1080, Dol:10.1007/s12541-014-0439-1.

[20] Noordin, M.Y., Venkatesh, V.C., Sharif, S., Elting, S., Abdullah, A. (2004). Application of response surface methodology in describing the performance of coated carbide tools when turning AISI 1045 Steel. Journal of Materials Processing Technology, vol. 145, no. 1, p. 46-58, Dol:10.1016/S09240136(03)00861-6. 